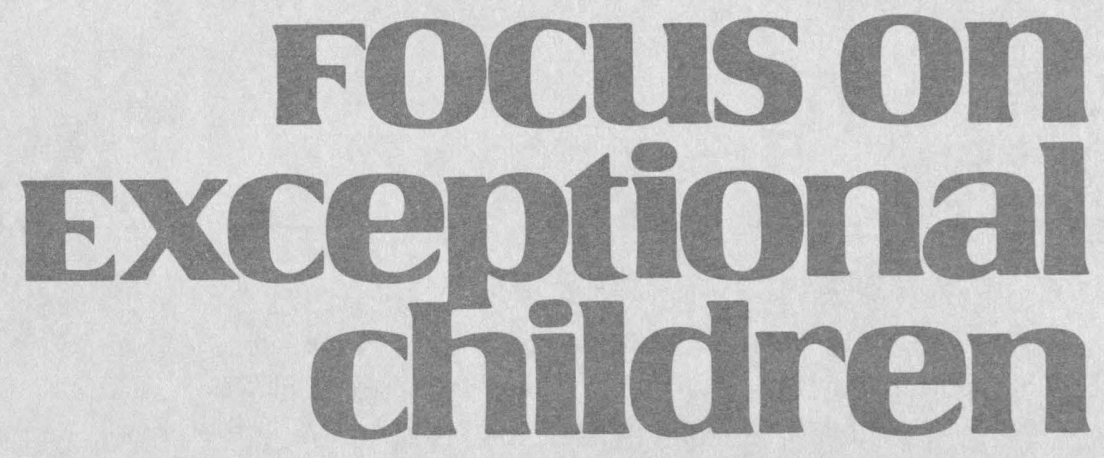

\title{
Disadvantaged Gifted Learners At-Risk for Educational Attention
}

Joyce VanTassel-Baska, James Patton, and Doug Prillaman

Two of the most neglected populations within the rubric of gifted education are (a) individuals whose talents may not be actualized because they are culturally different from the mainstream culture and (b) socially and economically disadvantaged individuals. These populations of students frequently are overlooked for special programs by school districts whose identification procedures fail to find them or whose standards for program entry are above the tested levels that many of these students achieve.

Furthermore, even when these students are found and placed in programs, little attention is given to the background cultural and socioeconomic factors that may seriously affect their performance in special programs and their future achievements beyond these programs. Consequently, the following questions warrant attention:

1. Who are these disadvantaged gifted students, and how do we find them?

2. What common and differential provisions should be made for them in schools?

3. What types of additional facilitation of talent development would be most useful to them?

These questions are fundamental to examining the problems and issues associated with this population.

\section{WHY THE NEED TO FOCUS ON THESE NEGLECTED GIFTED?}

Many educators and politicians would question the wisdom of targeting resources for such small-incidence populations within the larger segment of gifted students. Studies have shown, for example, that most gifted learners come from higher socioeconomic backgrounds (Sears \& Sears, 1980; VanTassel-Baska \& Willis, 1988). Thus, we are looking for a minority within the already limited population of gifted learners. But there are important reasons to pursue this issue:

Joyce VanTassel-Baska is Director, Center for Gifted Education, James Patton is Director of Teacher Education, and Doug Prillaman is Professor of Special Education. All three authors are at the College of William and Mary in Virginia. 
1. Our sense of a low-incidence rate is not substantiated, for the most part, by data. It is limited by the restrictions we place on the meaning of the term gifted. Historically, more students who came from mainstream culture and advantaged home and school backgrounds have been identified as part of the gifted population. Yet, even when we look within restricted definitions according to standardized testing protocols, we find sizable numbers of students, such as $15.5 \%$ in an eight-state regional talent search, or some 2,800 students in seventh and eighth grades (VanTasselBaska \& Chepko-Sade, 1986) meeting a criterion for economic disadvantagement. Thus, the incidence rate of disadvantaged gifted learners may be far greater than we have assumed.

2. There is a clear under-representation of minority students, particularly blacks, in gifted programs at the $\mathrm{K}-12$ level of schooling (Baldwin, 1985). The disparity between

\section{FOcus on
Exceptional children}

ISSN 0015-511X FOCUS ON EXCEPTIONAL CHILDREN (USPS 203-360) is published monthly except June, July, and August as a service to teachers, special educators, curriculum specialists, administrators, and those concerned with the special education of exceptional children. This publication is annotated and indexed by the ERIC Clearinghouse on Handicapped and Gifted Children for publication in the monthly Current Index to Journals in Education (CIJE) and the quarterly index, Exceptional Children Education Resources (ECER). It is also available in microfilm from Xerox University Microfilms, Ann Arbor, MI. Subscription rates: Individual, \$27 per year; institutions, $\$ 36$ per year. Copyright (c) 1989, Love Publishing Company. All rights reserved. Reproduction in whole or part without written permission is prohibited. Printed in the United States of America. Second class postage is paid at Denver, Colorado. POSTMASTER: Send address changes to:

$$
\begin{gathered}
\text { Love Publishing Company } \\
\text { Executive and Editorial Office } \\
1777 \text { South Bellaire Street } \\
\text { Denver, Colorado } 80222 \\
\text { Telephone (303) } 757-2579
\end{gathered}
$$

Edward L. Meyen

University of Kansas

Glen A Vergason Georgia State University

Richard J. Whelan University of Kansas Medical Center
Carolyn Acheson Senior Editor minority representation in the general population and in gifted programs is an issue that must be addressed in a pluralistic society.

3. Colleges and universities, as well as selected professions, are still experiencing an under-representation of minorities capable of meeting entry standards.

4. The gap between low socioeconomic status (SES) and higher SES level is widening and, contrary to popular opinion, the upward mobility rate of lower SES individuals is less than 3\% (Sennett \& Cobb, 1972).

5. The plight of the underclass black family, which is experiencing an increasing rate of single parentage, teenage pregnancy, and high unemployment, points to a need for increased interventions for the children in such situations who constitute the new poor and a sizable segment of tomorrow's adult population.

6. Gifted education has been seen as "elitist," addressing the concerns of a group of learners that many perceive as not being in need of special services, based on their advantaged socioeconomic status. Although such charges clearly do not reflect an appreciation of the need to attend to individual differences in schooling, regardless of the nature or type of difference, gifted educators need to be cognizant of

\section{STATEMENT OF OWNERSHIP, MANAGEMENT AND CIRCULATION}

Date of Filing: October 15, 1989

Title of Publication: FOCUS ON EXCEPTIONAL CHILDREN

Frequency of Issue: Monthly except June, July, and August

Location of Known Office of Publication: 1777 S. Bellaire St., Denver, CO 80222 Location of Headquarters of Publisher: 1777 S. Bellaire St., Denver, CO 80222 Name and Address of Publisher, Editor, and Managing Editor: Stanley F. Love, 1777 Bellaire St., Denver, CO 80222

Owner: Stanley F. Love

Extent and Nature of Circulation:

$\begin{array}{lrr}\text { Total No. Copies Printed } & \begin{array}{c}\text { Average No. Copies } \\ \text { Each Issue During } \\ \text { Preceding 12 Months }\end{array} & \begin{array}{c}\text { Single Issue } \\ \text { Nearest } \\ \text { Filing Date }\end{array} \\ \text { Paid Circulation } & 4,471 & 4,955 \\ \quad \text { Sales through Dealers, etc. } & 0 & 0 \\ \quad \text { Mail Subscriptions } & 3,520 & 3,745 \\ \text { Total Paid Circulation } & 3,520 & 3,745 \\ \text { Free Distribution } & 350 & 375 \\ \text { Total Distribution } & 3,870 & 4,120 \\ \text { Office Use and Left Over } & 601 & 835 \\ \text { Total } & 4,471 & 4,955\end{array}$

I certify that the statements made by me above are correct and complete.
Stanley F. Love Publisher 
this charge. As a field, we need to focus attention and resources on finding talented learners whose needs may be understood more readily and then clarify the importance of providing a needs-based education to all who show exceptional promise.

It is precisely these neglected gifted learners who do not have the support structures necessary to make it on their own. It is this population of learners that is in the greatest need of programs and services to help optimize their human potential. And it is this population that is at greatest risk of being forgotten in the context of both gifted and general education.

\section{REVIEW OF THE LITERATURE ON DISADVANTAGED GIFTED LEARNERS}

A recent 3-year study of key demographic features of "disadvantaged" gifted learners in the Midwest defined disadvantaged in purely economic terms (VanTassel-Baska \& Willis, 1988). Large-scale sociological studies have focused on consideration of a father"s education and occupational status as the key variables (Jencks, 1972). Other recent efforts, within the field of gifted education focused on minority status and cultural difference as important variables in defining the term (Baldwin, 1985, Frasier, 1980).

No one definition appears to be clearly accepted by the field, for these variables can occur singly or in combination (Baldwin, 1985). The result of such variance can be seen in the state of California's omnibus definition of disadvantaged gifted that considers all of the following diverse factors: environmental, economic, cultural, language, and social.

Studies that have been done on disadvantaged gifted populations based on the omnibus definition have focused on four needs:

1. The need to use nontraditional measures to identify the disadvantaged student (Bernal \& Reyna; 1974, Bruch, 1978; Frasier, 1979; Torrance, 1971).

2. The need to recognize cultural attributes and factors in deciding identification procedures (Baldwin, 1985; Gay, 1978; Samuda, 1975; Miller, 1974; Witty, 1978).

3. The need to focus on strengths in nonacademic areas, particularly in creativity and psychomotor domains (Bruch, 1975; Hilliard, 1976; Torrance, 1977).

4. The need to create programs that address noncognitive skills and that enhance motivation (McLelland, 1978; Moore, 1978).
A recent study commissioned by the Secretary of Education cited the following statistical conditions in our schools as indicative of the need to address the issue of disadvantaged gifted learners more specifically:

- Minority students are underrepresented in programs designed to serve gifted and talented students. Although minorities comprise $30 \%$ of public school enrollment, they represent less than $20 \%$ of the students selected for gifted and talented programs.

- Whereas students from low-income backgrounds comprise $20 \%$ of the student population, they make up only $4 \%$ of students who perform at the highest levels on standardized tests (those who score at the 95 th percentile or above).

- High school seniors from disadvantaged families (in which the mother did not complete high school) are less than half as likely to have participated in gifted and talented programs as are more advantaged seniors.

- Disadvantaged students are far less likely to be enrolled in academic programs that can prepare them for college and are about half as likely to take coursework in advanced math and science than are more advantaged students. Only $2 \%$ of high school seniors from poor families take calculus, whereas approximately $7 \%$ of those from more advantaged backgrounds do.

(U.S. Department of Education, 1989)

Table 1 coalesces the research findings on successful interventions with disadvantaged learners across several study areas. By synthesizing these findings across types of studies, we emerge with a clearer picture of some generic interventions that appear to work well, given the nature of the population. These interventions include:

1. Early and systematic addressing of the needs of these children.

2. Parental involvement in the educational program model.

3. Effective schools' strategies (e.g., time on task, school leadership).

4. Use of experiential and "hands-on" learning approaches.

5. Use of activities that allow for student self-expression.

6. Use of mentors and role models.

7. Involvement of the community.

8. Counseling efforts that address the issue of "cultural values" in facilitating talent development. 
TABLE 1

The Disadvantaged Student: Research Topics and Successful Interventions

Research Topics

Early Intervention

School and Classroom

Environment

Effective Teachers

Language Development

Mathematics and Science

Counseling

Gifted Disadvantaged

\section{Successful Interventions}

Preschool programs

Small adult-child ratio

Parent participation

Service to families

Motivated leadership/principal expectations

Supervision of teachers

Teacher morale

Emphasis on reading instruction

Communication with parents/parental involvement

Structured learning environments

Staff development

Matching of instruction to learning style/diagnostic-prescriptive teaching

Use of student ideas

Praise and encouragement

Verbal recognition of student feelings

Time on task

More activities per period

Teaching the English language

Acting out what is read

Using ethnic literature

Employing creative writing

Using familiar concrete objects as teaching tools and hands-on learning techniques

Using minority role models

Educating and involving parents

Focusing on the value of math and science

Extending time through out-of-school programs

Providing accelerated study through universities and special schools

Providing career awareness programs

Teaching problem-solving strategies

Using cognitive therapy techniques

Using mentors/role models

Respecting minority culture and related issues

Exploring cultural identity issue

Focusing on future career roles

Early intervention

Community involvement

Using mentors

Community involvement

Early counseling

Providing hands-on learning experiences 
Based on these findings, it seems apparent that some general directions have been identified for intervention with disadvantaged gifted learners. It remains for the field of gifted education to translate these areas into systematic program development efforts.

\section{A NATIONAL STUDY}

Concern for the culturally different and socioeconomically disadvantaged learner prompted us to explore the nature and extent of programs and services for these populations of gifted students throughout the United States. The study was organized around three basic areas of inquiry:

1. Determining the philosophical and definitional considerations used to address these special populations of gifted learners.

2. Ascertaining the major approaches the states utilized to identify and provide program interventions for these populations.

3. Determining the level and extent of state funding patterns, policies, procedures, and program standards for these learners.

The study was organized in three phases. Phase 1 consisted of a survey of all 50 states and territories seeking answers to the areas of inquiry outlined previously. Phase 2 involved a survey of all local school districts nominated by their states for having active programs for disadvantaged gifted learners. Phase 3 included the development of a series of 12 case studies probing the nature of exemplary programs across the United States for these learners. This article focuses on highlights from Phases 1 and 2 of the study.

\section{PHILOSOPHICAL AND DEFINITIONAL CONSIDERATIONS}

Just as the concern for, or interest in, increasing the representation of minorities and low socioeconomic learners in programs for the gifted has been espoused recently by researchers (Baldwin, 1985; Frasier, 1989; Richert, 1987; VanTassel-Baska \& Willis, 1988), data from the responding states indicate a general moderate to high level of philosophical orientation in this regard. Yet, as can be gleaned from the subsequent discussions regarding definitional structure, few states actually are operationalizing that philosophical orientation.
Although the literature has consistently supported the definitional structure of low SES as a major variable that should be accounted for in assessment and identification techniques designed to find gifted students (Baldwin, 1985; VanTassel-Baska \& Willis, 1988), a limited number of states include low SES as a frequently used factor in identifying students for gifted programs.

The states report race as being a slightly more frequently used factor than SES or an amalgam of race and SES in the process of identifying students for gifted programs. Interestingly, however, $21.2 \%$ (18) of the states responding to the survey indicated that they did not include the variable of race at all in the process of identifying students for gifted programs. This last finding is significant in that this variable, rooted in historical and environmental precursers, is generally understood to be a significant factor to consider in developing assessment and identification techniques necessary to uncover the hidden talents of "disadvantaged" learners (Baldwin, 1985)

Because only a minority of states utilize factors of "disadvantagement" in defining students who are eligible for gifted programs, it is not surprising that the majority of responses to questions relating to inclusion of variables such as environmental factors, socioeconomic factors, linguistic factors, cultural factors, and ethnicity in state definitions for gifted students was in the negative direction (see Table 2).

Although cultural differences were reported by the largest percentage of states $(32.7 \%)$ as the most often used factor of "disadvantagement" used in state definitions for gifted students, the largest percentage of the responding states $(38.5 \%)$ has no provision for considering "disadvantagement" in the state definitions. Further, although states reported race as the most frequently used factor in the process of identifying students for gifted programs, only eight states include this factor in their public definitions of gifted students.

Generally, the findings indicate that although states have been consistent in their philosophical support of cultural and racial diversity, they have lagged in incorporating these concerns for equity and pluralism into the definitional structures of their gifted programs. Given the present and projected increase of culturally and racially diverse student populations and students from low socioeconomic backgrounds in public schools, implications of the lack of congruence between states' philosophies regarding policies and these demographic factors cause concern.

Who disadvantaged gifted learners are and the size of the 


\section{TABLE 2}

\section{Factors of Disadvantagement Used in State Definitions for Gifted Students}

\author{
$\mathrm{N}=52$ \\ Frequency of Use \\ Types of Factors Used \\ By States Percent*
}

No inclusion of
disadvantaged
considerations in
state definitions
Consideration of
cultural differences

20

38.5

Consideration of

ethnicity status

17

32.7

Socioeconomic

considerations

14

26.9

Linguistic

considerations

13

25.0

Consideration of

environmental factors

11

21.2

*Percentages over $100 \%$ are caused by overlapping responses to categories.

pool from which they might be identified require systematic definition at state and local levels. Minority status and low income status are variables that any local district might examine in relationship to students within each group who show promise on standardized measures, and therefore should be considered for special programming at early stages of development.

\section{IDENTIFICATION AND INTERVENTION ISSUES}

Several perspectives are associated with examining the identification and intervention approaches states and local districts use in focusing on disadvantaged gifted learners. One of these perspectives is equality of treatment. Many states reported no difference in either identification or intervention for the disadvantaged gifted when compared to other gifted learners, based on a conception that equal treatment was legally and politically the most appropriate strate- gy. This mode of thinking has several strands. One strand argues that the goal of gifted programs is to educate leaders for American society; thus, mainstream culture and values must be assimilated in order to participate in realizing that goal. Another strand argues that gifted programs should educate for "giftedness" regardless of other factors; thus, other kinds of differences should be minimized in favor of best practices for a population of learners based on discernible advanced development. A third strand of this position holds that differentiating identification or program standards based on low SES or race is an insult to those youngsters and ultimately serves them poorly in an educational sense.

A second perspective is that of equity of affirmative action. This concept holds that minority students should be included in special programs, such as gifted education, at a level commensurate with their representation in the general population. Because traditional approaches to identification have not found minority students in these numbers, both nontraditional instruments and selection processes should be tried to meet the affirmative action goal. Some states and several local school districts ascribe to this idea in principle and may even meet established quotas; yet support mechanisms for retention and success in gifted programs usually is not assured in such contexts; and data are scanty regarding this issue.

A third perspective worthy of citing is the principle of individualization, deeply ingrained in the philosophy of gifted education. Differentiation in identification and intervention would occur most naturally at the level of an individual child, not at the level of an ethnic group or SES category. Consequently, some states could not begin to comment effectively on the survey questions that inferred group treatment based on characteristics beyond aptitude.

The majority of state directors of gifted programs hold to the first and third perspectives as ways of interpreting the seemingly limited provisions for disadvantaged gifted learners at the state level. These perspectives also affect the interpretation of this section of the study. Except for a few states that responded affirmatively to the question of differential services, results regarding identification and intervention practices are duplicative with other populations of gifted learners.

The state questionnaire revealed that directors of state programs perceived their states as embracing a moderate stance toward a broadened conception of giftedness in terms of identification issues, with a mean rating of 3.3 on a 5.0 scale. Nevertheless, the full range of responses to this 
item reflected a great deal of individual state variation on the issue. Only 22 states responded that use of a broadened conception was extensive.

The data reveal a generally moderate view toward operationalizing a new conception of giftedness. Even though the field of gifted education has officially embraced an expanded view of who the gifted are in respect to categories (Marland, 1972), the movement in that direction on the part of states 16 years later is surprising. New theoretical and research work published in the late 1970s and early 1980s has also lent additional credibility to an expanded vision of giftedness (Feldman, 1983; Gardner, 1983; Renzulli, 1978; Sternberg, 1985). Yet clearly the states do not extensively hold these views, particularly as they might be reflected in standards for funding programs and services.

In the area of nonbiased assessment techniques, all of the states responding to the question indicated some use. But when queried further regarding specific aspects of a nonbiased assessment protocol that might be employed, extent of use dropped dramatically. One component of many nonbiased assessment protocols, for example, is the use of nontraditional tests or use of different norming standards for an existing test. Yet $48.1 \%$ of the states indicated little or no use of such testing measures, as contrasted to the $19.2 \%$ who indicated only a little use of nonbiased assessment techniques.

This discrepancy may be interpreted in several ways. One interpretation may be that the respondents are not familiar with the specific components of a nonbiased assessment protocol, even though they react affirmatively to the terminology. Another interpretation may be that respondents view techniques such as observation by teachers and parents as more indicative of what is meant by nonbiased assessment. A third interpretation, however, is that reported use of nonbiased assessment techniques is greater than actual use when one examines individual components of an identification system.

The data also reflect strong use of traditional approaches to identifying the disadvantaged gifted, with $88.5 \%$ of the respondents indicating the use of norm-referenced tests and $90.4 \%$ using teacher nominations. No other techniques were so extensively used in the identification process. Still, the limited numbers of disadvantaged students in gifted programs would lead us to believe that greater use of nontraditional measures is needed to identify this population. The mean response to this item was 4.4 , and all states who responded to the item reported some use. Twelve states reported using additional procedures, which vary consider- ably from one another. No clear pattern of use emerged.

Currently, support for early intervention programs in general is viewed as the best policy initiative that might be enacted (National Committee for Economic Development, 1988). Not coincidentally, this is the area in which research evidence of long-term effects is the strongest (Brandt, 1986; Lazar, 1982; Schweinhart, 1985). Yet, with our most promising learners among the disadvantaged, this intervention approach is still under-utilized.

Although one might see merit in not differentiating basic programs and services for the disadvantaged gifted, lest they be denied the best quality program available, there is little basis for the support of not building beyond that basic delivery system to include more specialized services from which they might uniquely profit. Academic self-competence usually is not an issue for advantaged gifted learners, but it may be for disadvantaged ones (VanTassel-Baska, et al., in press). Thus, the need for additional opportunities for counseling, mentorships, and special tutorials seems warranted. We also have ample evidence that these students, even those who perform well on typical in-grade standardized tests, do not score as well as their advantaged counterparts on more powerful test measures (VanTassel-Baska \& Willis, 1988). Thus, intervention opportunities that can assist these students with accessing advanced skills also seem warranted.

Clearly, demographic trends reflect the need for greater, rather than less, attention to at-risk populations. As the vehicle in schools for enhancing talent development, gifted education is in a unique position to make a significant impact on this population. But the field must unify around a common understanding of who the disadvantaged are, how they can be found, and what interventions may be the most important for them to receive. Without a major federal initiative in this area, individual states clearly become the logical focus in this area.

As the data in this study suggest, however, a focus on the disadvantaged gifted is not a major priority area within the state department framework, with a few notable exceptions. Consequently, if we are interested in enhancing efforts in this area, policymakers at the state level must become more cognizant of the issues and find ways to incorporate it into state standards and funding formulas.

\section{PROGRAM STANDARDS ISSUES}

None of the states said they had separate state-developed program standards for disadvantaged gifted students. In 
fact, when asked this question, $53.1 \%$ of the states $(n=26)$ responded "no." The largest percentage of respondents, $44.9 \%(n=22)$, indicated that their state program standards were the same for the disadvantaged gifted and gifted students who are not identified as disadvantaged.

The data indicate that $82.7 \%$ of the states $(n=43)$ employ no state initiatives to monitor LEA implementation of programs for disadvantaged gifted students. But $17.3 \%(n=9)$ of the states indicated their state had initiatives to monitor local programs for including disadvantaged gifted students in the gifted program.

When asked if special materials, handbooks, guidelines had been developed by their state, $69.2 \%$ of the respondents $(n=36)$ stated "no." Similarly, six states, representing $11.5 \%$ of the total survey, gave no response to this question. But $19.2 \%(n=10)$ indicated that these materials either exist or are in the process of being developed.

The final question on the survey asked whether data were available on the number of disadvantaged gifted students being served in each state. Forty-six $(88.5 \%)$ of the respondents replied that these data were not available. Six (11.5\%) states responded affirmatively.

In its 1983 report, A Nation at Risk, the National Commission on Excellence in Education stated, "The Federal Government, in cooperation with states and localities, should help meet the needs of key groups of students such as the gifted and talented" (p. 32). Four years later Congress passed the first federal initiative to aid education for gifted and talented students. This meager bill, a $\$ 20$ million authorization, is included in the larger Omnibus Education Bill and provides funds for research, personnel preparation, and innovative projects. Since approval of the bill in 1988, \$8 million currently have been appropriated, but the extent of the funds to be allocated to the disadvantaged gifted issue is yet to be determined.

States vary widely in terms of interest or ability to assist localities in developing and maintaining gifted programs. Figure 1 depicts the level of support by states (Mitchell, 1984).

Although attention to programs for gifted at the state and

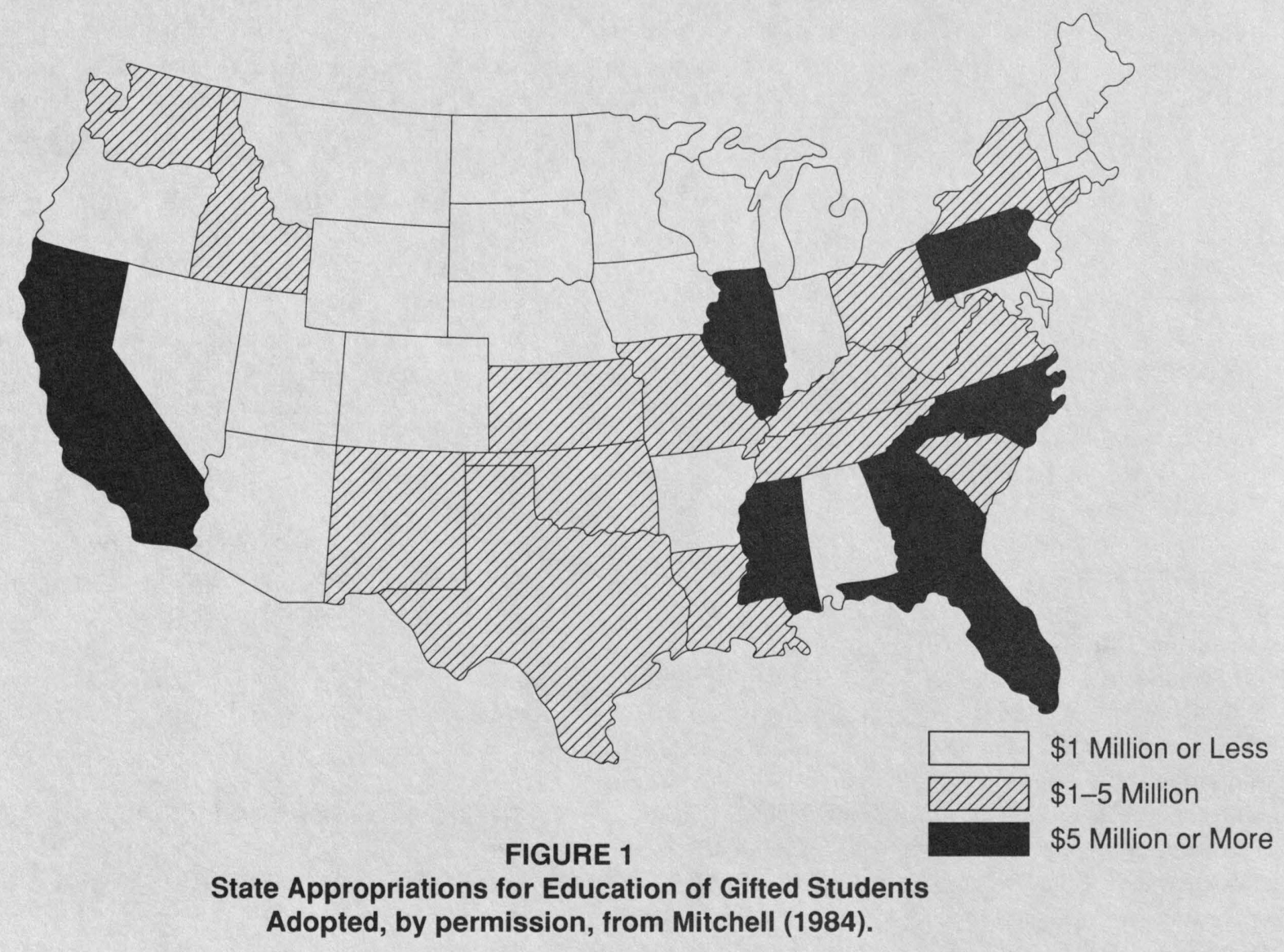


local levels has increased, state and local personnel apparently are not addressing the issue of program funding for one area of the under-represented population, the disadvantaged. Only one state reported that $20 \%$ of its funds was specifically allocated for this population of gifted students. When asked if other funding sources were available for the disadvantaged gifted, 50 states $(96.2 \%)$ did not respond.

The majority of states have developed standards for services to gifted and talented students. Those available for review provide ample information for localities to use in developing comprehensive programs. Maker (1986, p. 233) suggested that programs should adhere to seven components:

1. Provide a variety of options.

2. Be coordinated and articulated.

3. Have clearly defined policies and procedures.

4. Be well planned.

5. Demonstrate success through well designed, responsive evaluations.

6. Have a sound theoretical base.

7. Respond to the needs of the community.

Kaplan (1988) describes eight program standards as benchmarks of quality control:
1. Goals and objectives.
2. Decision making.
3. Monitoring.
4. Limitations.
5. Expenditures.
6. Perceptions.
7. Training.
8. Philosophy.

Several states do refer to the disadvantaged gifted in their state plans. In Mississippi, state programs are not mandated; however, local education agencies may design programs for four distinct populations-intellectually gifted, talented, gifted handicapped, and disadvantaged gifted. The State Department of Education (SDE) provides a specific definition of the gifted disadvantaged population. The regulations for approved programs and criteria for classification of gifted and talented students and culturally and educationally deprived students in Nebraska cite program criteria and selection procedures as two areas in which specific guidelines are to be followed. Within the program cri- teria, LEAs must provide evidence of planning to "assure access to programs by members of minority or educationally disadvantaged groups" (p. 4).

The selection procedures section of the Nebraska regulations specify that "instruments and criteria shall be chosen to reflect the emphasis of the differentiated curriculum to be provided and to protect members of minority or educationally disadvantaged groups from test bias discrimination" (p. 6). Likewise, the Minnesota Standards require that all instruments and procedures must be examined for cultural bias and "efforts must be employed to insure that representation and participation of all student populations in gifted and talented educational programs and include individuals of all races, creeds, national origins, genders, physical handicaps, or economic status" (p. 6).

Although most states do not have data on the number of disadvantaged gifted students served, several states report some estimates by racial or ethnic categories. In Florida, 5,202 culturally diverse students (Black Non-Hispanic, Hispanic, Asian, and American Indian) are receiving services in programs for the gifted and talented. Approximately $35 \%$ of the gifted students in California are members of minority populations; however, the number of low-income disadvantaged is unknown.

Data from the 52 states and territories reveal that little attention is given to proportional funding for various gifted populations. Only one state reported that funds $(20 \%)$ were specifically allocated to programs for disadvantaged gifted learners. The reasons for the lack of proportional funds probably are attributable to several factors. One, the total state budget for all gifted programs is relatively small. Two, states have yet to devote time and resources to under-represented populations (gifted women, underachievers, gifted handicapped). Program standards for the gifted disadvantaged population also are very limited. Only one state has developed specific standards regarding services to this population.

\section{SELECTED LOCAL PROGRAM ISSUES}

A survey was completed by 57 local school districts nominated by their state departments for focusing on disadvantaged gifted learners. Only 12 districts indicated that they had a definition of disadvantaged gifted learners, and of those, nine districts reported a definitional construct. Four included culturally different, minority, and the poor. Two sample definitions from these local districts are: 
1. ... those children regardless of race or ethnic group who may have language patterns and experiences, cultural backgrounds, economic disadvantages and/or educational disadvantages or differences which make it difficult for them to demonstrate their potential using traditional identification procedures.

2. Intellectually gifted children and youth are those who have potential for outstanding performance by virtue of superior intellectual abilities. Intellectually gifted means outstanding performance or potential for outstanding performance by virtue of superior intellectual abilities (K.A.R. 91-12-22 [q]). Both those with demonstrated achievement and those with minimal or low performance who give evidence of high potential in general intellectual ability, specific academic aptitudes, and/or creative thinking abilities are included in this definition.

Most frequently cited nontraditional identification measures used by responding districts were the Ravens Progressive Matrices $(n=5)$ and the Kaufman-ABC $(n=3)$. In the area of observation of children by adults, the most frequently used scales were locally developed $(n=9)$. Some districts used the Renzulli scales or portions thereof $(n=3)$. For creativity indices, the majority of districts reporting indicated use of the Torrance Test of Creative Thinking in some way $(n=7)$. The most frequently used norm-referenced tests were traditional, in-grade standardized achievement tests $(n=10)$. Additionally, a few districts used the Cognitive Abilities Test $(\mathrm{n}=3)$.

Very few of the local school districts responding to the survey showed congruence in their perspective about successes or problems in working with disadvantaged gifted students. The only perspectives indicated by at least two respondents were the following: Successes were perceived to be (a) achieving in the face of adversity, (b) strength of creative skills for personal and academic coping, (c) overcoming language difficulties, and (d) being identified for special programs. Problems were perceived to be in the following areas: (a) peer pressure, (b) a familial pattern that lacked resources to foster academic learning, (c) lack of self-esteem, (d) lack of funding for programs, (e) language deficiencies, and (f) transiency.

Even given the problems, respondents reported a hopeful note regarding the future education for these students:

"Getting this program in place has been a very slow process. I have received total support from staff and administration. The main problem is that the Mexican population comes and goes, and, therefore, ongoing instructional time is minimal. Our program goals usually go unrealized because of the transiency of our students during the implementation phase." (Coordinator A)

"Progress in improving the academic situation for gifted Native American students is very slow. However, we are gradually making progress. Our most important success has been the growth of acceptance, among Indian and white students, teachers, and parents, of there being gifted Indian students." (Coordinator B)

"Our programs are designed as supplemental, so we lack true program continuity. What we do find, though, is that teachers will send us students who don't "qualify" for traditional gifted/talented programs because these kids display a special talent. In our courses they shine because their strengths are being recognized and enhanced. They can only be successful. Many teachers have reported that even short-term exposure to our program enhances other kinds of in-school performance." (Coordinator J)

"Small rural schools with great family stability (in terms of location-families stay in one town for generations) develop expectations for certain kids because 'that's how the family is.' Many kids never are expected to achieve until they attend our special courses." (Coordinator K)

Based on the survey results from local school districts that were nominated by their state directors of gifted education for running special programs for disadvantaged gifted learners, we can discern key issues for this population at the local level. These issues tend to revolve around the dimensions of definition, identification, intervention, delivery, and evaluation approaches used in programs for this population.

\section{Definition}

Just as was found at the state level of analysis, only a limited definitional structure is in place for disadvantaged gifted learners. Most districts do not define the term and tend to operationalize it within the demands of the local 
context. For example, if a local district has a $90 \%$ minority population, the definition of disadvantaged tilts toward that minority group. If, on the other hand, the district is primarily low socioeconomic, made up of many ethnic groups, the focus tilts toward the issue of low SES. Although such a stance appears to be practical at the local level, it does limit the conception of who may need to be served under the rubric of the disadvantaged gifted.

A clear definition that recognizes different types and levels of disadvantagement is needed at the policy level in local school districts. Only through such an approach can low-SES students or minority students have a chance of service, particularly in districts in which their numbers do not dominate.

\section{Identification}

Several of the identification practices that these local school districts use appear promising, yet do not represent a stringent interpretation of the recommended practices from the literature. The most promising practices appear to be the most personalized-when a sensitive adult nominates or promotes a child in the school context. In these districts this has been a favored technique, and it has been found to be successful. The main danger inherent in its use, however, is in missing children who would do well in programs but were not discovered based on individual observations. All of the districts reported using multiple measures, however. This increases the likelihood that a child would be included through another approach.

A second promising practice appeared to be the "tryout" system, in which all students were given "gifted" activities to perform and then judged on the basis of their capacity to perform these activities in a classroom setting. Such an approach equalizes opportunity to demonstrate readiness without using tests as an arbitrary screening device. Its disadvantage, however, lies in the administrative arena of assuring all students access to tryouts in the regular classroom and training all teachers in a given context to provide the key activities. Nevertheless, it significantly strengthens the relationship between program expectations and student identification practices.

\section{Intervention}

Program intervention approaches used in these local districts mirror the state data regarding this issue. Traditional gifted program approaches are the norm, and more tailored or personalized program approaches are the exception. This finding is particularly surprising at the local level, where advertised programs for disadvantaged learners are provided. One might expect greater diversity in programming models and greater experimentation with differential program prototypes.

Of special note is the lack of systematic intervention at early ages, and the lack of counseling programs-two areas in which current studies and demonstration programs for these learners are consistent in regard to importance and efficacy. The need to provide more tailored and personalized interventions for disadvantaged gifted learners appears to be great, even in districts that are most responsive to their needs.

\section{Delivery}

These local districts did appear to be providing some differentiation for disadvantaged gifted learners at the level of classroom delivery, particularly as it related to keying in on individual characteristics of the students in the area of effective needs. Evidence of responsiveness to ethnic diversity also was prevalent through classroom techniques. The district data provide interesting portraits of perceived differences between advantaged and disadvantaged learners, with the greatest congruence among district respondents coming in the areas of (a) preference for oral over written work, (b) need for confirmation of ability, and (c) erratic performance. These perceived differences point toward a need for recognition of these factors and tailoring of curriculum and instruction to respond to them in deliberate ways.

\section{Evaluation}

Evaluation approaches that these districts utilize are, for the most part, standard ones used in the assessment of efficacy in all gifted programs. Thus, these programs experience the same problems in evaluation that are apparent in the field as a whole-an over-reliance on attitudinal perceptions of various groups about the program and a lack of student impact data. In fact, only a few of these programs were able to produce valid student impact data, even though the majority of them have been in place for several years. If we are to learn and advance as a field on this issue, there will have to be well designed evaluation studies of existing programs. Little current evidence indicates that such data exist or can be utilized effectively to advance our knowledge. 


\section{Conclusion}

The local district questionnaire has provided interesting insights into several dimensions of working with disadvantaged gifted learners. It further substantiates the general picture provided by the state survey that concrete policies at all levels are lacking regarding service to this population. Moreover, it yielded some promising identification practices and classroom delivery approaches. It corroborated findings from the state questionnaire also regarding lack of differentiated programs and limited evaluation data.

\section{OVERALL RECOMMENDATIONS}

The recommendations of this national study emerge out of a careful consideration of the data available and the noticeable lack of data in several key areas of the questionnaire probes. An attempt was made to recommend policy based on three central aspects of the study: definitional issues, identification and intervention, and program standards and funding. The policy recommendations have been generated for consideration at state and local levels, although they carry implications for national policy as well. The major recommendations of the study are:

\section{We should eliminate the use of the term "disadvan- taged."}

In describing culturally diverse populations, for example, the term disadvantaged carries a negative connotation. Cultures differ from each other; inherently, no one culture or class is superior to another. Accordingly, "cultural diversity" merely acknowledges the condition of such status without placing a value judgment on such a condition.

In an attempt to create awareness of inequities in our educational system, we have resorted to negative terminology. Like the word "handicapped," "disadvantaged" carries both a negative connotation and a generic notion of deficit or deficiency. This generic notion is problematic because individuals can be both disadvantaged and resilient, handicapped and gifted. And because the term is so generic, it frequently creates its own meaning in a particular local context.

To identify children who may be at risk for educational opportunities commensurate with their abilities because of a variety of factors, such as "disadvantaged," is to diffuse the issue in a way that blocks appropriate interventions. It is much more appropriate to consider the leading factors contributing to at-risk status-low socioeconomic status, member of an ethnic minority, handicapped in a specific way, a child of an unstable home environment (e.g., alcoholism, abuse), or language deficiency. These factors should be seen as the basis for special identification and intervention approaches whether they are present in $1 \%$ of a given school district population or $80 \%$ of that population. And in contexts where "at-risk" and "at-promise" conditions both prevail, gifted educators are obligated to intervene.

The terminology of "unserved" and "under-served" also have been used frequently to describe this population. Unfortunately, because of the stage of development of the field of gifted education, these terms only further confuse the issue because many other sub-populations of gifted learners - the highly gifted, gifted girls, the young primary gifted child, and certain categories of giftedness such as leadership-remain un- or under-served. Consequently, the "at-risk" factors that focus our attention on sociological issues of context are more useful for formulating policy.

\section{We need to translate expressed philosophical con-} cerns for "at-risk" learners into definitional structures of giftedness.

All levels of data collection have a strong orientation toward wanting these learners to be included in gifted programs. Yet, at the point of entry into the structure of the program-namely, the operational definition-few states and local districts focus on an inclusionary statement. It is as if rhetoric is expected to carry over into policy without deliberately planning for it. Until educational institutions explicitly define who they mean by "at-risk" gifted learners and seek to identify and program for them, the current status of service will show little change.

A suggested example of a definitional structure that focuses on the specific factor of disadvantagement is:

a. Students who come from low-income families in which the parents' educational and occupational status is also commensurately low.

b. Students who come from different cultural backgrounds that require an understanding of the cultural perspective in order to find and serve them appropriately.

c. Students who possess limited English proficiency because of recency of immigration or community norms.

d. Students who possess physical or learning handicaps that may mask their potential. 
e. Students who come from dysfunctional family backgrounds (e.g., single parent, abuse, alcoholism).

f. Students who possess a combination of these characteristics.

\section{We must recognize that "at-risk" gifted learners} share many commonalities with all gifted learners and yet vary in significant ways.

This knowledge requires educators to combine unique elements used in defining, identifying, and developing programs for these learners, with qualitatively different approaches needed for all gifted learners. Just as the gifted share common characteristics with all learners, so too does the "at-risk" gifted learner share many characteristics with both typical learners and other gifted learners.

Nevertheless, it is in the area of deviance that our efforts to program must focus. Special characteristics create special educational needs that should be addressed differentially if we are to enhance the capacities of at-risk children. Thus, a recognition of deviance and a willingness to address it are required in charting a qualitatively distinctive program for these learners. Special characteristics also imply a need for seeing these students in different ways. Thus, an identification protocol that is cognizant of background factor differences is necessary.

\section{We need to initiate the use of multiple measures,} among them assessment measures perceived to be nonbiased, for the identification and selection of at-risk students into gifted programs.

Based on our questionnaire studies and the case study data just presented on identification, districts should have little reason not to employ a combinational model for identification that places some validity on nonbiased assessment procedures. As can be seen from some case study examples, the protocol may vary as long as an effort is made to include in the context instrumentation that appears less biased.

A selection committee process or selection that considers child-centered issues beyond the numbers added on the identification form also appears prudent. If our goal is to find promising at-risk learners, we must find ways to establish a pool of such students within each of the risk factor categories, a task calling for nontraditional approaches.

5. We should encourage the use of a "try-out' program for all students nominated to the gifted program in which

\section{responsiveness to differentiated classroom curriculum becomes a part of the selection paradigm.}

Too much emphasis on gifted program development has been placed on the identification process in a vacuum, devoid of significant interaction to the actual curriculum provided to students. This situation is especially problematic when we consider at-risk students who are being overlooked in our quest to find the traditionally gifted learner. Consequently, if we reverse the order of program development, so that enriched opportunities in the classroom become one level of identification, we will have established an important, yet frequently missing, link between identification and curriculum intervention.

\section{We need to develop program prototypes for use with} atypical gifted learners.

The study points up a real need for prototypical models for intervention with at-risk gifted learners. Although the recommendations in Table 1 are useful in that they reflect the current literature, it is equally important that our programs begin to generate successful models that work in the local context. At present there is a real need in this area. Most of the interventions used with these learners are the standard for all gifted programs.

Providing equal treatment programs has merit, but greater merit is inherent in providing additional levels of programming to at-risk learners-programming that addresses some of their unique needs. This value-added concept of programming might occur in the context of the regular gifted program through an IEP model, individual contract, or more personalized delivery of services. Special groupings of such learners based on the particular risk factor might have merit in some contexts.

\section{We need to develop individual services such as tutor-} ing, mentoring, and counseling for at-risk gifted learners.

Insight into what works for at-risk learners suggests the importance of personalized services, delivered by a caring individual who understands the nature of the child's status and has ideas for helping him or her negotiate education successfully. This individual represents an important link for at-risk learners in the schools.

Because volunteer personnel likely would have to be utilized for such a service, two key groups should be considered: (a) community groups containing large numbers of 
highly skilled retirees and unemployed individuals, and (b) student groups, of college age and even high school students, who could work in such a program as their community service contribution. If businesses want to assist schools, organizing a community support network for these learners would be a wonderful way to contribute to the individual lives of such children.

\section{We should consider a "matching funds" model to encourage program development for at-risk gifted stu- dents.}

Just as volunteer assistance may be necessary to activate the level of personalized service these learners require, so, too, funding models will have to go beyond the gifted budget in order to make inroads into viable programs and services. Linkages to programs focusing on each "at-risk" factor would seem to be the best strategy, coupled with the funding initiatives in a local context that frequently may focus on this type of child if the incidence rate is perceived substantial enough. This type of shared funding must be systematically explored so that we have the flexibility to try new practices and prototypes with these learners. Without additional incentive funding, our current level of limited programming is apt to prevail.

\section{We need to collect systematic data on at-risk students being served in gifted programs.}

As the study has revealed, few local school districts and states are capable of providing incidence data regarding atrisk gifted populations. Moreover, even those capable of this level of reporting are not systematically collecting evaluation data on classroom/program effectiveness with this kind of learner. Consequently, some funding and energy should be targeted at data collection efforts on this population. Because the evaluation problem is endemic of the gifted education field in general, accomplishing this needed program measure may be difficult. Yet the success of future work with disadvantaged gifted learners depends heavily on our having access to good data about program practices.

\section{REFERENCES}

Baldwin, A. (1985). I'm Black but Look at Me, I am also Gifted. Gifted Child Quarterly. 31, 180-185.

Bernal, E.M., \& Reyna, J. (1974). Analysis and identification of giftedness in Mexican American children: A pilot study. In B.O. Boxton (Ed.), A resource manual of information on educating the gifted and talented. Reston, VA: Council for Exceptional Children.
Brandt, R. (1986). On long-term effects of early education: A conversation with Lawrence Schweinhart. Educational Leadership, 44(3), 14-18.

Bruch, C.B. (1975). Assessment of creativity in culturally different gifted children. Gifted Child Quarterly, 19(2), 164-174.

Bruch, C.B. (1978). Recent insights on the culturally different gifted. Gifted Child Quarterly, 22(3), 374-393.

Feldman, D. (Ed.). (1983). Developmental conceptions of giftedness. San Francisco: Jossey-Bass.

Frasier, M.M. (1979). Rethinking the issue regarding the culturally disadvantaged gifted. Exceptional Children, 45(7), 538-542.

Frasier, M.M. (1980). Programming for the culturally diverse, in J. Jordan \& J. Grossi, An Administrator's Handbook on Designing Programs for the Gifted and Talented, Reston, VA: Council for Exceptional Children.

Frasier, M. (1989). A perspective on identifying black students for gifted programs In Maker, J. (Ed.), Critical issues in gifted education (Vol. 2). Rockville, MD: Aspen Publications.

Gardner, H. (1983). Frames of mind. New York: Basic Books.

Gay, J. (1978). A proposed plan for identifying black gifted children. Gifted Child Quarterly, 22(3), 353-360.

Hilliard, A. (1976). Alternatives to IQ testing: An approach to the identification of the gifted in minority children (Rep. No. 75175). San Francisco: San Francisco State University.

Jencks, C. (1972). Inequality. New York: Basic Books.

Kaplan, S.N. (1988, October). Maintaining a gifted program. Roeper Review, II(1). October 1988.

Lazar, I. (1988). Measuring the effects of early childhood programs. Community Education Journal, 15(2), 8-11.

Maker, C.J. (Ed.). (1986). Critical Issues in Gifted Education: Defensible Programs For the Gifted. Austin, TX: Pro Ed.

Marland, S. (1972). U.S. Report to Congress on the Gifted and Talented. Washington, DC: Government Printing Office.

McClelland, D.C. (1978). Managing motivation to expand human freedom. American Psychologist, 33, 201-210.

Miller, L. (1974). The testing of black students: A symposium. Englewood Cliffs, NJ: Prentice-Hall.

Mitchell, P.B. (1984). Mapping a state advocacy plan for the gifted. Journal for the Education of the Gifted, 7(4), 252-69.

Moore, B. (1978). Career education for disadvantaged gifted high school students. Gifted Child Quarterly, 22(3), 332-337.

National Commission on Excellence in Education. (1983). A Nation At Risk: The Imperative For Educational Reform. Washington, DC: United States Department of Education.

National Committee for Economic Development. (1988). Children In Need. Washington, DC.

Olszewski, P., Kulreke, M., Willis, G., \& Krasney, N. (1987). A study of the predictors of success in fast paced classes and the validity of entrance scores, Evanston, IL: Northwestern University, Center for Talent Development.

Renzulli, J. (1978). What makes giftedness: Re-examining a definition. Phi Delta Kappan, 60, 180-184.

Richert, S. (1987). Rampant problems and promising practices in the identification of disadvantaged gifted students. Gifted Child Quarterly, 31, 149-154.

Samuda, R.J. (1975). Psychological testing of American minorities: Issues and consequences. New York: Dodd, Mead. 
Schweinhart, L.J. (1985). The Preschool Challenge. High/Scope Early Childhood Policy Papers, no. 4. Ypsilanti, MI: High/Scope Education Research Foundation.

Sears, P., \& Sears, R. (1980). 1528 little geniuses and how they grew, Psychology Today, February, 28-43.

Sennett, R., \& Cobb, J. (1972). The Hidden Injuries of Class. New York: Random House.

Sternberg, R. (1985). Beyond IQ. Cambridge, MA: Cambridge University Press.

Torrance, E.P. (1971). Are the Torrance Tests of Creative Thinking biased against or in favor of disadvantaged groups? Gifted Child Quarterly, 15, 75-80.

Torrance, E.P. (1977). Discovery and nurturance of giftedness in the culturally different. Reston, VA: Council for Exceptional Children.

United States Department of Education. (1989). No gifted wasted: Effective strategies for educating highly able, disadvantaged students in mathematics and science. Washington, DC: Government Printing Office.
VanTassel-Baska, J., \& Chepko-Sade, D. (1986). An incidence study of disadiantaged gifted students in the Midwest, Evanston, IL: Northwestern University, Center for Talent Development.

VanTassel-Baska, J., \& Willis, G. (1988). A three year study of the effects of low income on SAT scores among the academically able. Gifted Child Quarterly, 31, 169-173.

VanTassel-Baska, J., Olszewski, P., \& Kulieke, M. Differences between advantaged and disadvantaged populations on personality measures. (in press).

Witty, E.P. (1978). Equal educational opportunity for gifted minority children. Gifted Child Quarterly, 22(3), 344-352.

\section{Adapted Physical Education in the Mainstream}

\author{
Second Edition \\ Bryant J. Cratty \\ University of California, Los Angeles
}

Solve the problems of mainstreaming with this lively revision of the most comprehensive text available on adapted physical education. Totally rewritten, the text features new chapters on hyperactivity, fitness, infant stimulation, and awkwardness. Specific strategies and interventions are suggested for all the handicapping and health problems found among children birth to adult who require assistance from P.E. teachers, therapists, and related personnel.

Many photos and graphics illustrate the step-by-step procedures for making physical exercise and movement an enjoyable experience for all students. You'll refer to this valuable resource time and time again.

\section{SPECLAL FEATURAS}

Covers all handicapping and health conditions encountered in P.E. classes

Gives specific suggestions for integrating activities for handicapped and nonhandicapped students

Devotes a full chapter to the recently recognized problems of awkward children

Includes new material on attention defects, hyperactivity, and autism

\section{CONTENTS}

I The New Challenges of Physical Education in the Mainstream

Introduction and Overview/Laws, Trends, and Individual Programs/Evaluation: Teaching Roles and Strategies/Theories and Models About Movement Activities

\section{Sensory Impairments}

Visual Impairments/Hearing Impairments

\section{Behavioral and Learning Disorders}

Learning Disabilities/Emotional/Behavioral Disturbances/Mental Retardation/Speech and Language Impairments

IV Central Nervous System and Neuromotor Problems Awkwardness/Brain Injuries and Cerebral Palsy/Degenerative Diseases of the Nervous System/Epilepsy and Convulsive Disorders/Muscular Dystrophy and Other Muscular Disorders

V Fitness and Structural Problems

Obesity and Fitness/Body Build and Posture/Orthopedic Impairments/Arthritis

VI Cardiovascular, Pulmonary, and Metabolic Disorders Heart Disease/Hemophilia and Sickle Cell Anemia/Asthma and Other Respiratory Conditions/Juvenile Diabetes

\section{Interventions}

Infant Stimulation/Self-Control and Attention/Rhythm, Dance, and Music/Locomotion and Variations/Balls and Other Missiles/ Body Awareness and Tumbling/Aquatics/Swimming/Games That Teach Things

8826/hardbound/ISBN 0-89108-13n-5

\section{LOVE PUBLISHING COMPANY 1777 South Bellaire Street Denver, Colorado 80222}




\section{Professional update}

\section{College Planning for Gifted Students}

by Sandra L. Berger

This new resource has been well received by high school students who are facing complicated choices for their future. It presents a six-year plan that guides the gifted student through decision-making based on personal goals, values, and learning style. The premise is that college planning is a matter of finding a good match between student and college.

The first step for the student is to learn about himself or herself. Then the student goes on to learn about colleges-where to look, what to ask. Finally, the reader is guided through the application process itself. The author includes suggestions on what counselors can do, what parents can do, and what teachers can do. Special characteristics of the pre-adolescent, culturally different, female, underachieving, and learning disabled student are identified, with special suggestions offered.

To order, write: Council for Exceptional Children/ERIC, 1920 Association Dr., Reston, VA 22091-1589. For more information, call Jean Nazzaro, CEC, 703/620-3660, or Sandra Berger, 703/938-3784.

\section{Patterns of Influence on Gifted Learners}

\section{edited by Joyce L. VanTassel-Baska and} Paula Olszewski-Kubilius

One of the books in a series on gifted edited by James Borland, this new paperback focuses on the role of the home, the self, and the schooling process in talent development. The contributors, including Wendy Roedell, Michael Piechowski, Harry Passow, James Gallagher, Linda Silverman, and other leaders in the field, competently address the various topical areas.

Replete with facts, statistics, and research, the chapters are nevertheless easy to read. Case history, anecdotal, and illustrative narrative create a balanced presentation and keep the book interesting. Specific issues include the influence of family values, environment, the growth of self, curriculum development and evaluation, career counseling, and others.

This 264-page book is available from Teachers College Press, Columbia University, New York, NY 10027.

\section{American Speech-Language-Hearing Association}

November 17-20, 1989

Cervantes Convention Center, St. Louis, Missouri

Contact: ASHA (301) 897-5700

The Association for Persons with Severe Handicaps

December 7-9, 1989

San Francisco Hilton Hotel

San Francisco, California

Contact: TASH (206) 523-8466

Technology and Media Division

Council for Exceptional Children

January 11-13, 1990

Lexington, Kentucky

Contact: Joel Mittler

School of Education

Long Island University

Brookville, New York 11548

\section{Association for Children and Adults with Learning Disabilities}

February 21-24, 1990

Anaheim Hilton Hotel

Anaheim, California

Contact: ACLD (412) 341-1515

\section{Council for Exceptional Children}

\author{
April 23-27, 1990 \\ Toronto, Ontario, Canada \\ Contact: CEC \\ 1920 Association Drive \\ Reston, Virginia 22091
}

American Association on Mental Retardation

May 27-31, 1990

Atlanta, Georgia

Contact: AAMD (202) 387-1968 